\title{
GAMBARAN TINGKAT PENGETAHUAN TENTANG PENCABUTAN GIGI PADA MASYARAKAT KELURAHAN KOMBOS BARAT BERDASARKAN PENDIDIKAN DAN PEKERJAAN
}

\author{
${ }^{1}$ Vita A. Lethulur \\ ${ }^{2}$ Damajanti H. C. Pangemanan \\ ${ }^{3}$ Aurelia Supit
}

\author{
${ }^{1}$ Kandidat Skripsi Program Studi Pendidikan Dokter Gigi Fakultas Kedokteran \\ Universitas Sam Ratulangi Manado \\ ${ }^{2}$ Bagian Fisiologi Fakultas Kedokteran Universitas Sam Ratulangi \\ ${ }^{3}$ Program Studi Pendidikan Dokter Gigi Fakultas Kedokteran \\ Universitas Sam Ratulangi Manado \\ Email: Vitaamelialethulur@yahoo.com
}

\begin{abstract}
Dental health as an integral part of public health needs attention of the government and society. Efforts to provide dental care to the community in the field of curative usually a tooth extraction. Lack of knowledge about tooth extraction causes the general public, especially people in West Kombos village avoid prolonged pain even though the tooth can still be maintained. This study aimed to describe the level of public knowledge about tooth extraction based on education and jobs in West Kombos village. This was a cross sectional study. Data were taken by using stratified random sampling method in which the number of samples taken at 5 areas. The result showed that the level of knowledge based on public education 39.7\% were in primary school education and the level of knowledge based on jobs $35.87 \%$ were housewives. Conclusion: Based on education and jobs, the level of knowledge about tooth extraction among West Kombos people were largely categorized bad.
\end{abstract}

Keywords: knowledge, tooth extraction

\begin{abstract}
Abstrak: Kesehatan gigi sebagai bagian integral dari kesehatan umum perlu mendapat perhatian dari pemerintah maupun masyarakat. Upaya pemberian pelayanan kesehatan gigi pada masyarakat dibidang kuratif umumnya berupa pencabutan gigi. Kurangnya pengetahuan tentang pencabutan gigi menyebabkan masyarakat umum khususnya masyarakat di kelurahan Kombos Barat melakukan pencabutan agar terhindar dari rasa sakit berkepanjangan meskipun gigi tersebut masih bisa dipertahankan. Penelitian ini bertujuan untuk mengetahui gambaran tingkat pengetahuan masyarakat tentang pencabutan gigi berdasarkan pendidikan dan pekerjaan di kelurahan Kombos Barat. Penelitian ini menggunakan rancangan potong lintang. Data diambil menggunakan metode proportional stratified random sampling dimana jumlah sampel diambil pada 5 lingkungan. Hasil penelitian menunjukkan bahwa tingkat pengetahuan masyarakat berdasarkan pendidikan yaitu $39,7 \%$ pendidikan sekolah dasar dan tingkat pengetahuan berdasarkan pekerjaan yaitu $35,87 \%$ ibu rumah tangga. Simpulan: Tingkat pengetahuan masyarakat kelurahan Kombos Barat tentang pencabutan gigi berdasarkan pendidikan dan pekerjaan sebagian besar dikategorikan buruk.
\end{abstract}

Kata kunci: pengetahuan, pencabutan gigi

Berbicara masalah kesehatan secara umum, tidak terlepas dari masalah kesehatan gigi dan mulut khususnya. Kesehatan gigi sebagai bagian integral dari kesehatan umum perlu mendapat perhatian dari pemerintah maupun masyarakat. ${ }^{1}$ Upaya pemberian pelayanan kesehatan gigi pada 
masyarakat umumnya berupa pencabutan gigi. $^{2}$

Berdasarkan Riset Kesehatan Nasional (RISKESDAS) 2007 jenis perawatan yang diterima penduduk yang mengalami masalah gigi dan mulut yaitu $87,6 \%$ dan pencabutan pencabutan gigi $38,5 \%$ yang bertambah seiring bertambahnya usia. ${ }^{3}$

Pengetahuan berasal dari kata dalam bahasa inggris yaitu knowledge. Dalam encyclopedia of philosophy dijelaskan bahwa pengetahuan adalah kepercayaan yang benar. ${ }^{4}$ Pengetahuan adalah hasil dari tahu yang terjadi melalui proses sensoris khususnya mata dan telinga terhadap objek tertentu. ${ }^{5}$

Pengetahuan merupakan upaya mencari tahu dari yang tidak tahu menjadi tahu. Kurangnya pengetahuan tentang pencabutan gigi menyebabkan masyarakat umum khususnya masyarakat di kelurahan Kombos Barat berpendapat bahwa jika gigi mereka sakit, hal yang mudah dan terbaik ialah mencabut gigi agar terhindar dari rasa sakit. Persepsi masyarakat ini disebabkan oleh kurangnya perhatian dari institusi kesehatan khususnya perawat dan dokter gigi, untuk memberikan sosialisasi kepada masyarakat setempat.

Kelurahan Kombos Barat berada di kecamatan Singkil kota Manado memiliki jumlah penduduk 5.595 jiwa. Masyarakat di kelurahan Kombos Barat memiliki pendidikan yang berbeda-beda dan sebagian besar masyarakat hanyalah lulusan sekolah dasar dengan pekerjaan mayoritas ialah buruh lepasan. Berdasarkan faktor-faktor di atas melatarbelakangi peneliti untuk mengadakan penelitian dengan pengambilan sampel dengan umur 26-55 tahun. Mengingat pentingnya pengetahuan tentang pencabutan gigi sebagai upaya peningkatan kesehatan, serta belum ada yang melakukan penelitian di kelurahan Kombos Barat tentang pencabutan gigi maka peneliti menganggap penting untuk melakukan penelitian ini.

\section{METODE PENELITIAN}

Penelitian ini merupakan penelitian deskriptif dengan rancangan penelitian cross sectional study (potong lintang). Penelitian ini dilakukan di kelurahan Kombos Barat pada bulan September 2014. Populasi yang diteliti yaitu masyarakat kelurahan Kombos Barat yang berusia 2655 tahun sebanyak 2.642 orang. Kriteria inklusi masyarakat yang pernah mendapat perawatan pencabutan gigi, berdomisili di kelurahan Kombos Barat, bersedia dengan sukarela dijadikan subjek penelitian. Masyarakat yang mengalami cacat mental dan tidak dapat berkomunikasi dengan baik dimasukkan dalam kriteria ekslusi. Besar sampel diperoleh menggunakan rumus slovin. Pengambilan sampel dilakukan secara propotional stratified random sampling yang diambil pada 5 lingkungan. Variabel penelitian ini yaitu pengetahuan pencabutan gigi, pendidikan dan pekerjaan.

Pengetahuan pencabutan gigi merupakan seberapa besar informasi yang diketahui masyarakat tentang pencabutan gigi yang berkaitan dengan apa yang bisa dan tidak bisa dilakukan serta dampak dari pencabutan gigi itu sendiri. Pengetahuan pencabutan gigi diukur dengan kuisioner menggunakan 10 pertanyaan dalam skala Gutman dengan skor Pengetahuan baik skor 8-10 dan pengetahuan buruk skor 1-7.

Pendidikan ialah proses pembelajaran yang dilalui oleh manusia dengan cara bertahap melalui jalur formal, yaitu SD, SMP, SMA, D1, D3, S1, S2 dan S3.

Pekerjaan ialah kegiatan yang dilakukan manusia untuk mencari uang dalam bentuk profesi seperti TNI, POLRI, PNS, Pegawai Swasta, Wiraswasta dan Buruh untuk memenuhi kebutuhan seharihari.

Instrument yang digunakan dalam penelitian ini yaitu kuesioner. Prosedur penelitian yaitu setelah mendapat izin dari kelurahan, masyarakat setempat yang dikategorikan orang dewasa dibagikan kuesioner untuk diisi dan dikembalikan kepada peneliti. Cara pengambilan data yaitu Pengambilan data masyarakat setempat diambil dari kantor kelurahan. Peneliti mulai membagikan kuesioner pada warga setempat dengan kuisioner yang sudah diisi data pasien terlebih dahulu, 
seperti Nama, Tempat Tanggal lahir , Umur, Pendidikan terakhir dan Pekerjaannya. Data yang diperoleh diolah dan dianalisis berdasarkan distribusi frekuensi dan disajikan dalam bentuk tabel frekuensi.

\section{HASIL PENELITIAN}

Kelurahan Kombos Barat terletak di provinsi Sulawesi Utara kecamatan Singkil kota Manado. Kelurahan Kombos Barat memiliki 5.595 jiwa dengan latar belakang pendidikan lebih banyak sekolah dasar dan pekerjaan mayoritas ialah buruh. Kelurahan Kombos Barat memiliki lima lingkungan dengan fasilitas satu kantor kelurahan, satu Puskesmas, dua sekolah dan lima panti asuhan.

Berdasarkan hasil penelitian yang dilakukan di kelurahan Kombos Barat, subjek yang diteliti pada penelitian ini berjumlah 348 jiwa. Karakteristik responden berdasarkan jenis kelamin menunjukkan bahwa perempuan berjumlah 185 orang $(53,16 \%)$ dan laki-laki berjumlah 163 orang $(46,84 \%)$ (Tabel 1).

Tabel 1. Distribusi subjek penelitian berdasarkan jenis kelamin

\begin{tabular}{ccc}
\hline Jenis Kelamin & $\mathrm{n}$ & $\%$ \\
\hline Laki-laki & 163 & 46,84 \\
Perempuan & 185 & 53,16 \\
Total & 348 & 100
\end{tabular}

Pada karakteristik responden berdasarkan usia, menunjukkan bahwa paling banyak responden dengan usia dewasa awal (26-35 tahun) sebanyak 152 orang $(43,7 \%)$ dan yang paling sedikit responden dengan usia dewasa akhir (36-45 tahun) sebanyak 79 orang $(22,7 \%)$ (Tabel 2).
Tabel 2. Distribusi subjek penelitian berdasarkan usia

\begin{tabular}{ccc}
\hline Usia(tahun) & $\mathrm{n}$ & $\%$ \\
\hline $26-35$ & 152 & 43,7 \\
$36-45$ & 79 & 22,7 \\
$46-55$ & 117 & 33,6 \\
Total & 348 & 100 \\
\hline
\end{tabular}

Pada karakteristik responden berdasarkan tingkat pendidikan menunjukkan bahwa tingkat pendidikan SD 141 orang $(40,52 \%)$, SMA/SMK 115 orang $(33,05 \%)$, SMP 65 orang $(18,7 \%)$, S1 15 orang $(4,31 \%)$, tidak sekolah 6 orang $(1,72 \%)$, S2 3 orang $(0,86 \%)$, D1 2 orang $(0,57 \%)$, dan S3 1 orang $(0,29 \%)$ (Tabel 3).

Tabel 3. Distribusi subjek penelitian berdasarkan tingkat pendidikan

\begin{tabular}{ccc}
$\begin{array}{c}\text { Tingkat } \\
\text { Pendidikan }\end{array}$ & $\mathrm{n}$ & $\%$ \\
\hline Tidak & 6 & 1,72 \\
Sekolah & & \\
SD & 141 & 40,52 \\
SMP & 65 & 18,68 \\
SMA/SMK & 115 & 33,05 \\
D1 & 2 & 0,57 \\
S1 & 15 & 4,31 \\
S2 & 3 & 0,86 \\
S3 & 1 & 0,29 \\
Total & 348 & 100 \\
\hline
\end{tabular}

$\begin{array}{ccr}\text { Pada } & \text { karakteristik } & \text { responden } \\ \text { berdasarkan } & \text { tingkat } & \text { pekerjaan }\end{array}$
menunjukkan bahwa wiraswasta 25 orang $(7,18 \%)$, swasta 49 orang $(14,08 \%)$, IRT 125 orang $(35,92 \%)$, satpol pp 2 orang $(0,575 \%)$, tukang jahit 2 orang $(0,575 \%)$, petani 5 orang $(1,44 \%)$, buruh 56 orang (16,09\%), pembantu 2 orang $(0,575 \%)$, sopir 13 orang $(3,74 \%)$, ojek 10 orang( $2,87 \%)$, nelayan 3 orang $(0,86 \%)$, tekniker mesin 2 orang $(0,575 \%)$, pensiunan 5 orang $(1,44 \%)$, pengacara 1 orang $(0,29 \%)$, dan yang tidak bekerja 39 orang $(11,21 \%)$ Tabel 4).

Gambaran Tingkat Pengetahuan tentang Pencabutan Gigi berdasarkan Kuesioner 
Lethulur, Pangemanan, Supit: Gambaran tingkat pengetahuan...

Pada Tabel 5 dapat dilihat pengetahuan masyarakat di kelurahan Kombos Barat dengan frekuensi pengetahuan buruk berjumlah 342 orang $(98,28 \%)$ dan frekuensi pengetahuan baik berjumlah 6 orang $(1,72 \%)$.

Tabel 4. Distribusi subjek penelitian berdasarkan pekerjaan

\begin{tabular}{ccc} 
Pekerjaan & $\mathrm{n}$ & $\%$ \\
\hline Wiraswasta & 25 & 7,18 \\
Swasta & 49 & 14,08 \\
IRT & 125 & 35,92 \\
Satpol PP & 2 & 0,575 \\
Tukang jahit & 2 & 0,575 \\
Petani & 5 & 1,44 \\
Buruh & 56 & 16,09 \\
Pembantu & 2 & 0,575 \\
Guru & 7 & 2,01 \\
Dosen & 2 & 0,575 \\
Sopir & 13 & 3,74 \\
Ojek & 10 & 2,87 \\
Nelayan & 3 & 0,86 \\
Tekniker & 2 & 0,575 \\
Mesin & & \\
Pensiunan & 5 & 1,44 \\
Pengacara & 1 & 0,29 \\
Tidak Kerja & 39 & 11,21 \\
Total & 348 & 100 \\
\hline
\end{tabular}

Tabel 5. Distribusi frekuensi tingkat pengetahuan tentang pencabutan gigi berdasarkan kuesioner

\begin{tabular}{ccc}
\hline Kategori & $\mathrm{n}$ & $\%$ \\
\hline Baik & 6 & 1,72 \\
Buruk & 342 & 98,28 \\
Total & 348 & 100 \\
\hline
\end{tabular}

Gambaran Tingkat Pengetahuan tentang Pencabutan Gigi berdasarkan Pendidikan

Pada tabel 6 ditemukan tingkat pengetahuan tentang pencabutan gigi berdasarkan pendidikan lebih banyak yaitu tingkat pengetahuan buruk SD 138 orang $(39,7 \%)$, SMA/SMK 113 orang $(32,4 \%)$, SMP 65 orang $(18,7 \%)$, S1 14 orang (4\%), tidak sekolah 6 orang $(1,7 \%)$, S2 3 orang $(0,9 \%)$, D1 2 orang $(0,6 \%)$, dan S3 1 orang $(0,3 \%)$.
Tabel 6. Distribusi frekuensi tingkat pengetahuan tentang pencabutan gigi berdasarkan pendidikan

\begin{tabular}{ccccccc}
\hline & \multicolumn{9}{c}{ Tingkat Pengetahuan } & \multicolumn{2}{l}{ Total } \\
Pendidika & \multicolumn{2}{c}{ Baik } & \multicolumn{2}{c}{ Buruk } & & \\
n & $\mathrm{n}$ & $\%$ & $\mathrm{n}$ & $\%$ & $\mathrm{n}$ & $\%$ \\
\hline Tidak & 0 & 0 & 6 & 1,72 & 6 & 1,72 \\
Sekolah & & & & & & \\
SD & 3 & 0,8 & 13 & 39,6 & 14 & 40,5 \\
& & 6 & 8 & 6 & 1 & 2 \\
SMP & 0 & 0 & 65 & 18,6 & 65 & 18,6 \\
& & & & 8 & & 8 \\
SMA/SM & 2 & 0,5 & 11 & 32,4 & 11 & 33,0 \\
K & & 7 & 3 & 7 & 5 & 5 \\
D1 & 0 & 0 & 2 & 0,57 & 2 & 0,57 \\
S1 & 1 & 0,2 & 14 & 4,02 & 15 & 4,31 \\
& & 9 & & & & \\
S2 & 0 & 0 & 3 & 0,86 & 3 & 0,86 \\
S3 & 0 & 0 & 1 & 0,29 & 1 & 0,29 \\
Total & 6 & 1,7 & 34 & 98,2 & 34 & 100 \\
& & 2 & 2 & 8 & 8 & \\
\hline
\end{tabular}

Tabel 7. Distribusi frekuensi tingkat pengetahuan tentang pencabutan gigi berdasarkan pekerjaan

\begin{tabular}{ccccccc}
\hline Pekerjaan & \multicolumn{3}{c}{ Tingkat Pengetahuan } & \multicolumn{2}{c}{ Total } \\
& \multicolumn{2}{c}{ Baik } & \multicolumn{2}{c}{ Buruk } & & \\
& $\mathrm{n}$ & $\%$ & $\mathrm{n}$ & $\%$ & $\mathrm{n}$ & $\%$ \\
\hline Wiraswasta & 3 & 0,86 & 22 & 6,32 & 25 & 7,18 \\
Swasta & 0 & 0 & 49 & 14,08 & 49 & 14,08 \\
IRT & 2 & 0,575 & 123 & 35,345 & 125 & 35,92 \\
Satpol PP & 0 & 0 & 2 & 0,575 & 2 & 0,575 \\
Tukang & 0 & 0 & 2 & 0,575 & 2 & 0,575 \\
jahit & & & & & & \\
Petani & 0 & 0 & 5 & 1,44 & 5 & 1,44 \\
Buruh & 0 & 0 & 56 & 16,09 & 56 & 16,09 \\
Pembantu & 0 & 0 & 2 & 0,57 & 2 & 0,575 \\
Guru & 0 & 0 & 7 & 2,01 & 7 & 2,01 \\
Dosen & 0 & 0 & 2 & 0,57 & 2 & 0,575 \\
Sopir & 0 & 0 & 13 & 3,74 & 13 & 3,74 \\
Ojek & 0 & 0 & 10 & 2,87 & 10 & 2,87 \\
Nelayan & 0 & 0 & 3 & 0,86 & 3 & 0,86 \\
Tekniker & 0 & 0 & 2 & 0,57 & 2 & 0,575 \\
Mesin & & & & & & \\
Pensiunan & 0 & 0 & 5 & 1,44 & 5 & 1,44 \\
Pengacara & 0 & 0 & 1 & 0,29 & 1 & 0,29 \\
Tidak Kerja & 1 & 0,29 & 38 & 10,92 & 39 & 11,21 \\
Total & 6 & 1,72 & 342 & 98,28 & 348 & 100 \\
\hline
\end{tabular}

Gambaran Tingkat Pengetahuan tentang Pencabutan Gigi berdasarkan Pekerjaan

Pada penelitian ditemukan tingkat pengetahuan tentang pencabutan gigi berdasarkan pekerjaan pada masyarakat kelurahan Kombos Barat yaitu pengetahuan buruk paling banyak ditemukan pada ibu 
rumah tangga dengan jumlah responden 123 orang $(35,3 \%)$ dan yang paling sedikit pada pengacara yaitu 1 orang $(0,3 \%)$.

\section{BAHASAN}

Pada penelitian yang dilakukan di masyarakat kelurahan Kombos Barat dengan jumlah sampel 348 jiwa, ditemukan subjek penelitian berdasarkan jenis kelamin yang paling banyak yaitu perempuan dengan jumlah responden 185 orang $(53,16 \%)$ dibanding laki-laki dengan frekuensi usia dewasa awal 26-35 tahun dengan tingkat pendidikan yang paling banyak sekolah dasar dengan jumlah responden 141 orang $(40,5 \%)$ dan pekerjaan yang paling banyak ialah ibu rumah tangga dengan responden 125 orang $(35,87 \%)$.

Berdasarkan hasil penelitian yang dilakukan dengan cara membagikan kuesioner pada masyarakat kelurahan Kombos Barat dengan jumlah 10 pertanyaan, diperoleh hasil bahwa pengetahuan masyarakat kelurahan Kombos Barat tentang pencabutan gigi dikategorikan pengetahuan buruk. Penelitian ini berbanding terbalik dengan penelitian yang dilakukan oleh Bayu di desa Molompar Utara kabupaten Minahasa Tenggara, karena pada hasil penelitiannya masyarakat yang berada di desa Molompar pengetahuannya dikategorikan baik. ${ }^{6}$ Hal ini disebabkan karena di desa Molompar terdapat puskesmas yang aktif sehingga pada saat mengalami masalah gigi dan mulut mereka akan memilih untuk berobat ke puskesmas sebaliknya di kelurahan Kombos Barat pelayanan puskesmas tidak berjalan dengan baik sehingga masyarakat malas untuk berobat. hal lain yang memengaruhi juga ialah kurangnya kesadaran masyarakat akan pentingnya kesehatan gigi dan mulut.

Tingkat pengetahuan tentang pencabutan gigi berdasarkan pendidikan dapat dilihat pada hasil penelitian ditemukan paling banyak responden dengan pendidikan terakhir SD berjumlah 138 orang $(39,7 \%)$ memiliki tingkat pengetahuan yang buruk dan yang paling sedikit pendidikan S3 berjumlah 1 orang $(0,3 \%)$. Pengetahuan dapat diperoleh melalui proses pendidikan yang berfokus pada proses mengajar dengan tujuan agar terjadi perubahan perilaku dari tidak tahu menjadi tahu. Interaksi individu dengan lingkungannya, baik di dalam lingkungan maupun di luar lingkungan memungkinkan seseorang lebih banyak menerima informasi. Pada saat penelitian dilakukan masyarakat kurang mengerti dan tidak mau mencari tahu informasi tentang pencabutan gigi serta bagaimana cara menjaga kesehatan gigi dan mulut. Peneliti juga menemukan jenjang pendidikan pada masyarakat kelurahan Kombos Barat tidak menjamin seberapa besar tingkat pengetahuan pada masyarakat di kelurahan tersebut. Menurut Notoatmodjo, pendidikan yang tinggi apabila tidak didukung dengan informasi melalui media massa akan memengaruhi pengetahuan seseorang, sebaliknya apabila pendidikan rendah namun seseorang bisa mencari informasi lebih luas melalui media massa maupun pendidikan non formal maka pengetahuannya akan lebih jauh daripada seseorang yang pendidikannya tinggi. ${ }^{6}$

Tingkat pengetahuan tentang pencabutan gigi berdasarkan pekerjaan dapat dilihat pada hasil penelitian ditemukan pekerjaan yang paling banyak memiliki pengetahuan buruk adalah ibu rumah tangga dengan jumlah 123 orang $(35,3 \%)$. Pekerjaan merupakan faktor yang memengaruhi pengetahuan. Ditinjau dari jenis pekerjaan yang sering berinteraksi dengan orang lain lebih banyak pengetahuan dibandingkan dengan orang tanpa ada interaksi dengan orang lain. Pengalaman belajar dalam bekerja yang dikembangkan memberikan pengetahuan dan keterampilan profesional serta akan dapat mengembangkan kemampuan dalam mengambil keputusan yang merupakan keterpaduan menalar secara ilmiah dan etik, ${ }^{7}$ namun pada data beberapa pekerjaan di atas dan penelitian yang dilakukan di lapangan ternyata pengetahuan mengenai pencabutan gigi pada masyarakat masih sangat kurang. Masyarakat yang 
mempunyai pekerjaan yang lebih banyak berinteraksi dengan orang lain malah pengetahuannya rendah akan pencabutan gigi, hal ini disebabkan karena tingkat ekonomi yang rendah dimana mereka hanya memikirkan bagaimana cara untuk mendapatkan uang untuk biaya hidup sehari-hari dan juga kurangnya fasilitas dari dinas kesehatan untuk mensosialisasikan bagaimana cara menjaga dan merawat kesehatan gigi dan mulut serta indikasi dan kontra indikasi dalam pencabutan gigi dan mulut.

\section{SIMPULAN DAN SARAN}

Berdasarkan pembahasan penelitian yang dilakukan dapat diambil kesimpulan sebagai berikut: tingkat pengetahuan masyarakat kelurahan Kombos Barat tentang pencabutan gigi berdasarkan pendidikan dan pekerjaan sebagian besar dikategorikan buruk. Saran bagi pemerintah diharapkan untuk pemerintah khususnya dinas kesehatan agar lebih banyak melakukan penyuluhan untuk menambah wawasan masyarakat tentang kesehatan gigi dan mulut, bagi institusi pendidikan dapat menjadi dasar untuk mengembangkan studi selanjutnya dan dalam prakteknya dokter gigi dapat memberikan edukasi pada masyarakat untuk meningkatkan kesehatan gigi dan mulut, dan bagi masyarakat diharapkan agar lebih banyak mencari informasi tentang masalah-masalah apa yang bisa terjadi pada kesehatan gigi dan mulut serta bagaimana cara untuk menjaga kesehatan gigi dan mulut.

\section{DAFTAR PUSTAKA}

1. Radifah S. Hubungan sikap dan pengetahuan masyarakat tentang pencabutan gigi di kabupaten Bone [Skripsi]. Makassar: FKG Unhas, 2004.

2. Arwana S. Tindakan ekstraksi gigi pada pasien dengan penyulit penyakit sistemik. PABMI Indonesian journal of oral and maxillofacial surgeons. 2007;10(1):1-9.

3. Badan penelitian dan pengembangan kesehatan departemen kesehatan RI. Riset kesehatan dasar 2007. Jakarta: Departemen Kesehatan RI. 2008.

4. Amsal B. Filsafat Ilmu (Edisi revisi). Jakarta: PT Raja Grafindo Persada, 2004.

5. Sunaryo. Psikologi untuk keperawatan. Jakarta. EGC. 2004. p.25.

6. Bayu W. Gambaran tingkat pengetahuan dan sikap masyarakat tentang pencabutan gigi desa Molompar Utara kabupaten Minahasa Tenggara [Skripsi]. Manado: FKG Unsrat, 2013.

7. Azwar S. Sikap manusia. Yogjakarta: Pustaka Belajar. 2005. p35. 